\title{
Sugars and Acids Influence Flavor Properties of Mango (Mangifera indica)
}

\author{
T.M.M. Malundo \\ U. S. Distilled Products, 1607 South 12th Street, Princeton, MN 55371
}

R.L. Shewfelt

Department of Food Science, University of Georgia, Athens, GA 30602

G.O. Ware

Department of Experimental Statistics, College of Agricultural and Environmental Sciences, University of Georgia, Athens GA 30602

\author{
E.A. Baldwin ${ }^{1}$ \\ U.S. Department of Agriculture, Agricultural Research Service, Citrus and Subtropical Products \\ Laboratory,600 Ave. S N.W., P.O. Box 1909, Winter Haven, FL 33883-1909
}

AdDitional InDEX wORDs. descriptive sensory panel, total soluble solids, titratable acidity

\begin{abstract}
Information on important flavor components for fruit and vegetables is lacking and would be useful for breeders and molecular biologists. Effects of sugar and acid levels on mango (Mangifera indica L.) flavor perception were analyzed. Twelve treatments, identified using a constrained simplex lattice mixture design, were formulated by adding sugar $(60 \%)$, citric acid $(40 \%)$, and water to an equal volume of mango homogenate. Using 150 -mm nonstructured line scales, a trained panel evaluated the treatments according to 11 flavor descriptors. Titratable acidity (TA), pH, and total soluble solids (TSS) were also determined. Acid concentration affected ratings for sweet, sour, peachy, pine/terpentine, astringent, and biting. Except for sour taste, all descriptors were affected by sugar content while increasing water increased intensities of all flavor notes. TA, pH, and TSS/TA correlated $(P<0.01)$ with and were useful predictors $(r>$ 0.80) of sour taste and chemical feeling descriptors astringent and biting. TSS, however, was not a particularly good indicator of sweetness $(r=0.72)$ or any other descriptor except possibly peachy $(r=0.79)$. It is evident from this study that sugars and acids enhance human perception of specific flavor notes in mango, including aromatics.
\end{abstract}

Mango (Mangifera indica L.) is a very popular specialty fruit in the United States (Vance Publishing Corp., 1994) and is of great economic importance to the tropical regions that produce them (Mitra and Baldwin, 1997; Narain et al., 1998). Its current popularity is attributed mainly to its unique flavor, aroma, and appearance. Flavor, especially, is a consumption attribute critical to consumer acceptability of mangoes (Gholap et al., 1986; Malundo et al., 1996).

Lack of attention to flavor compounds in breeding programs has led to flavor mediocrity in many fruit and vegetables. This has occurred because fruit and vegetable breeders have little information on flavor compounds available for use in selecting for this complex trait. Some information on mango flavor has been reported, but much is still not understood. Organic acids and sugars are key components in the perception of mango flavor as in most fruit (Medlicott and Thompson, 1985). The predominant acid is citric (Medlicott and Thompson, 1985; Lizada, 1993). On the other hand, as a result of starch hydrolysis from increased amylase activity during ripening (Fuchs et al., 1980; Tandon and Kalra, 1983), sucrose is the major sugar in the ripe fruit (Medlicott

Received for publication 1 Nov. 1999. Accepted for publication 25 Aug. 2000 South Atlantic Area, Agricultural Research Service, U.S. Department of Agriculture. Mention of a trademark or proprietary product is for identification only and does not imply a guarantee or warranty of the products by the USDA. The USDA prohibits discrimination in all its programs and activities on the basis of race, color, national origin, gender, religion, age, disability, political beliefs, sexual orientation, and marital or family status. We thank Julia Heggie and Holly Sisson for technical assistance. The cost of publishing this paper was defrayed in part by the payment of page charges. Under postal regulations, this paper therefore must be hereby marked advertisement solely to indicate this fact.

${ }^{1}$ To whom correspondence should be addressed; e-mail ebaldwin@ citrus.usda.gov. and Thompson, 1985; Tandon and Kalra, 1983; Vazquez-Salinas and Lakshminarayana, 1985). The main reducing sugar identified by Medlicott and Thompson (1985) and Vazquez-Salinas and Lakshminarayana (1985) was fructose while Selvaraj et al. (1989) reported glucose to be predominant. Conflicting reports on the relative concentrations of individual sugars present in mango at different stages of ripening were attributed to varying cultivars and storage conditions used (Medlicott and Thompson, 1985).

The effects of cultivar (Gowda and Ramanjaneya, 1994; Kapse et al., 1988; Kundu and Gosh, 1992;), stage of maturity (Morga et al., 1979; Shashirekha and Patwardhan, 1976; Tandon and Kalra, 1983), postharvest treatments (Kumar et al., 1992), and storage conditions (Vazquez-Salinas and Lakshminarayana, 1985) on sugar and acid levels in mango have been studied extensively. Acid levels are expressed frequently in terms of $\mathrm{pH}$ and titratable acidity (TA) while sugar concentrations are reported as total soluble solids content (TSS) (Kapse et al., 1988; Kumar et al., 1992; Kundu and Gosh, 1992; Medlicott and Thompson, 1985; Morga et al., 1979; Vazquez-Salinas and Lakshminarayana, 1985). Few investigators, however, have attempted to understand how varying concentrations of these components affect flavor perception of the fruit. This is important information for breeders and molecular biologists who seek to improve mango flavor through genetic manipulation using cultivar selection or identification of genes responsible for flavor quality. Kapse et al. (1988) determined that increasing total soluble solids while decreasing acidity increased flavor ratings of mango as determined by a panel of seven judges. However, the usefulness of such conclusions towards understanding the effects of sugar and acids on mango flavor is limited since the investigators failed to clearly define the type of panel (i.e., consumer, 


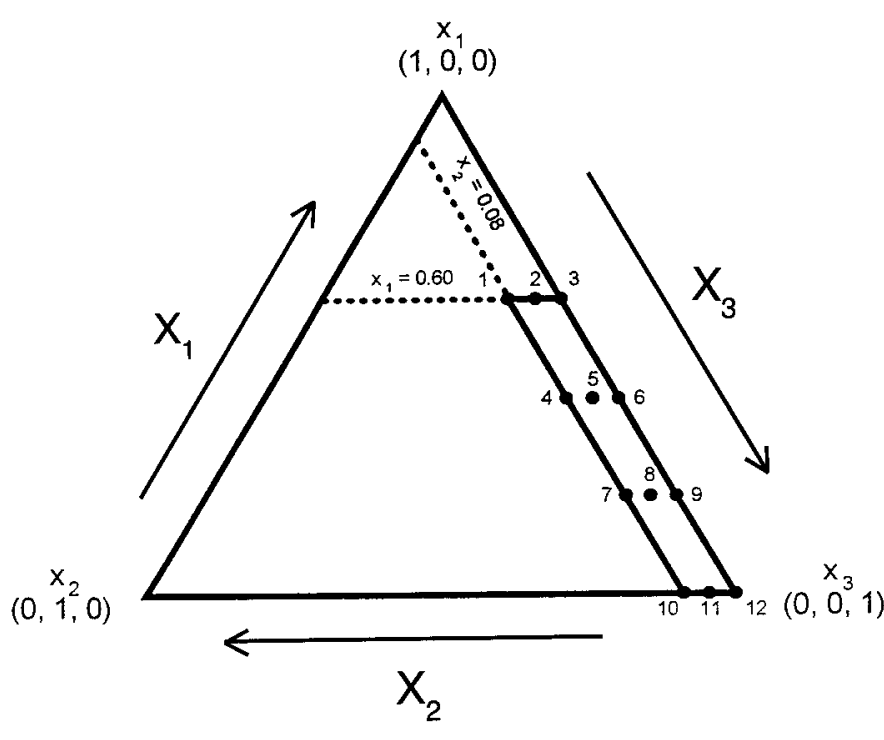

Fig. 1. Constrained region in the simplex coordinate system defined by the following restrictions: $0<\mathrm{x}_{1}<0.60$ and $0<\mathrm{x}_{2}<0.08$, where $\mathrm{x}_{1}$ and $\mathrm{x}_{2}$ are proportions of sugar and acid solutions, respectively. Component $\mathrm{x}_{3}$ represents proportion of deionized water. Points within the constrained region indicate design mixtures of a constrained simplex lattice experimental design. Points correspond to the following $\left(\mathrm{x}_{1}, \mathrm{x}_{2}, \mathrm{x}_{3}\right)$ coordinates : $1:(0.60,0.08,0.32), 2$ : $(0.60,0.04,0.36), 3:(0.60,0,0.40), 4:(0.40,0.08,0.52), 5:(0.40,0.04,0.56)$, $6:(0.40,0,0.60), 7:(0.20,0.08,0.72), 8:(0.20,0.04,0.76), 9:(0.20,0,0.80) 10:$ $(0.0,0.08,0.92), 11:(0.0,0.04,0.96)$, and 12: $(0,0,1)$

experienced, or trained) or scale (i.e., intensity or acceptability) used.

This study was conducted to determine the effects of varying sugar and acid concentrations on flavor properties of mango to better understand how flavor components impact our sensory perceptions. Another goal was to determine useful measurements that relate to flavor perception for mango. Currently, breeders and others interested in developing flavor traits in fruit and vegetables must rely on sensory analyses which are time consuming, expensive, and require much expertise. Determining the relationship of chemical measures to sensory data would allow their use in lieu of sensory studies to predict certain flavor properties. Thus, we hope to increase understanding of mango flavor and identify useful tools for breeders and molecular biologists for use in improving mango flavor quality.

\section{Materials and Methods}

SAMPle PREPARATION AND EXPERIMENTAL DESIGN. 'Tommy Atkins' mangoes were purchased in July, 1996 from a commercial mango distributor based in Homestead, Fla. Excess fruit were bought and only fully ripe mangoes, in good condition, and harvested at the morphologically mature stage as described by Medlicott et al. (1988) were used.

Ten batches of $600 \mathrm{~g}$ pulp from 30 fruit were homogenized using a 12-speed Oster blender (Oster Corp., Milwaukee, Wis.) and combined to form a composite sample. Mango homogenate was distributed among plastic containers which were immediately capped and stored at $-20 \pm 2{ }^{\circ} \mathrm{C}$ until use. The plastic containers were purchased specifically for the storage of mango samples.

Solutions of $60 \%$ (w/v in deionized water) sugar and $40 \%$ (w/v) citric acid (U.S.P.-F.C.C., J.T. Baker, Inc., Phillipsburg, N.J.) were prepared and stored at $5 \pm 2{ }^{\circ} \mathrm{C}$ until used. The sugar solution was prepared from a mixture of sucrose (table sugar) and fructose (D-fructose, U.S.P./N.F., Spectrum Chemical Mfg. Corp., Gardena, Calif.) combined in a 2 sucrose : 1 fructose ratio, the average ratio of sucrose to fructose in mango cultivars studied (Gowda and Ramanjaneya, 1994; Kumar et al., 1992; Kundu and Ghosh, 1992; Medlicott and Thompson, 1985; Tandon and Kalra, 1983; Vazquez-Salinas and Lakshminarayana, 1985). Before blending with an equal volume of mango homogenate (see below), mixtures of $60 \%$ sugar, $40 \%$ citric acid and deionized water were prepared in specific proportions resulting in a threecomponent constrained simplex lattice mixture design, as described by Cornell (1983) (Fig. 1). A similar design was developed in studying the effects of formulation on sensory, physical, and microbial properties (Malundo et al., 1994); and consumer acceptability (Malundo and Resurreccion, 1993) of liquid coffee whitener from peanut extract.

To approximate sugar and acid levels in mango cultivars already studied (Gowda and Ramanjaneya, 1994; Kapse et al., 1988; Kumar et al., 1992; Kundu and Ghosh, 1992; Medlicott and Thompson, 1985; Morga et al., 1979; Tandon and Kalra, 1983; Vazquez-Salinas and Lakshminarayana, 1985), the proportions of sugar and acid solutions used were limited to maximum levels of 0.6 and 0.08 , respectively.

Twelve mixture blends were identified and corresponded to the 12 points on the simplex coordinate system in Fig. 1. These consisted of coordinates of vertices and of uniformly spaced points on the face and sides of the constrained region of the polynomial equation representing a response of behavior over the restricted simplex region.

Frozen mango homogenate was thawed by immersing plastic containers in tap water. For each treatment, $250 \mathrm{~mL}$ sugar/acid mixture was prepared by combining water, and sugar and acid solutions according to the proportions mentioned above. The resulting mixture was then blended with $250 \mathrm{~mL}$ thawed mango homogenate. A $100 \mathrm{~mL}$ subsample was drawn from each treatment and stored in a closed plastic container at $-20 \pm 2{ }^{\circ} \mathrm{C}$ until use for chemical analysis. The remaining treatment blends were evaluated using sensory methods. Two replications were conducted.

Sensory Evaluation. The treatment blends were evaluated using a method modified from the Spectrum technique (Sensory Spectrum, Chatham, N.J.) for descriptive analysis (Meilgaard et al., 1991). The procedure calibrated panelists based on reference standards established for the Spectrum method but rated samples using 150-mm nonstructured line scales (Galvez and Resurreccion, 1990). This modified method was used previously in descriptive analysis of muffins (Holt et al., 1992a), tortillas (Holt et al., 1992b), whipped topping (Abdullah et al., 1993b), and coffee whiteners (Abdullah et al., 1993a; Malundo et al., 1994; Malundo and Resurreccion, 1993), and mungbean noodles (Galvez et al. 1995).

Ten judges, trained previously in the descriptive analysis technique employed, were chosen to participate in the evaluations. All had consumed mangoes previously and did not have any negative reaction towards the fruit.

The panelists were trained to evaluate the flavor of the treatment blends in six 1-h training sessions by the principal investigator. During training, panelists tasted $100 \%$ and $50 \%$ mango homogenate (diluted with an equal volume of deionized water) samples. The flavor terminology was developed using diluted mango homogenate. Panelists suggested descriptors and references for evaluating the flavor of samples presented (i.e., the 
Table 1. Flavor descriptors used to evaluate mango samples.

\begin{tabular}{ll}
\hline \hline Descriptor $^{2}$ & Definition \\
\hline Tastes & Taste stimulated by sugars like sucrose, fructose, and glucose \\
Sweet & $\begin{array}{l}\text { Taste stimulated by acids such as citric and malic } \\
\text { Taste stimulated by substances such as caffeine }\end{array}$ \\
Bitter & \\
Aromatics & Aromatic associated with ripe peach \\
Peachy & Aromatic common to both pine tar and turpentine \\
Pine/turpentine & Aromatic associated with boiled sweet potato \\
Sweet potato & Aromatic associated with ripe banana \\
Banana & Aromatic associated with newly cut grass \\
Grassy & Aromatic associated with orange rind \\
Orange peel & \\
Chemical feeling factors & The shrinking or puckering of the tongue surface caused by substances such as tannin and alum \\
Astringent & The stinging sensation felt on the tongue after drinking carbonated drinks such as soda \\
Biting &
\end{tabular}

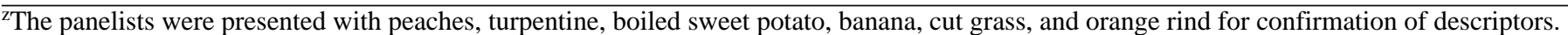

panelists developed their own terminology, such as sweet potato, banana, or peach. and were then presented with those materials during the training for confirmation). An initial list of 18 descriptors was generated during the first and second sessions. This number was reduced to 11 after subsequent training in which standard references were introduced to clarify terms (Rainey, 1986). The final list of descriptors used during evaluations, together with corresponding definitions, is tabulated in Table 1.

Except for the descriptors sweet and sour, as noted below, panelists were calibrated using reference standards established for Spectrum Analysis (Meilgaard et al., 1991). Intensities of standards, developed on a 15-point category scale, were adapted to the $150-\mathrm{mm}$ nonstructured line scale by multiplying by a factor of 10 . Since some treatment blends were expected to contain $18 \%$ to $28 \%$ sugar and $1.60 \%$ to $1.85 \%$ acid, sucrose $(12 \%, 24 \%$, and $36 \%)$ and citric acid $(0.7 \%, 1.4 \%$, and $2.1 \%)$ solutions were used as reference standards for the descriptors sweet and sour, respectively. These solutions were assigned intensity ratings by panelists along the $150-\mathrm{mm}$ line scale.

Based on ratings of reference standards already established, panelists then rated two mango standards, labeled Standard A and Standard B, for all flavor descriptors listed in Table 1. The mango standards were used by panelists as warm-up samples during evaluations (Malundo et al., 1994; Rutledge and Hudson, 1990; St. Angelo et al., 1992). These were 50\% mango homogenate, other than the experimental samples, selected after preliminary screening of test samples with varying intensities for flavor properties. The mango standards were intended to represent extremes in the expected range of mango flavor (but not necessarily representing the extremes on the $150 \mathrm{~mm}$ scale which was established with the Spectrum standards, Meilgaard et al., 1991). Standards A and B were prepared and stored at $-20 \pm 2{ }^{\circ} \mathrm{C}$ until needed. The intensity ratings assigned to all reference standards during training are listed in Table 2.

A standard for good performance was also set during training. Panelists were considered to be performing well when ratings were within $\pm 10 \mathrm{~mm}$ from the mean based on a 150 - $\mathrm{mm}$ line scale (Meilgaard et al., 1991).

Each replication of the experimental design was evaluated within two sessions. Therefore, each panelist rated six treatments per evaluation. Two replications of the design were evaluated within the same day, one in the morning and the other in the afternoon (i.e., each panelist evaluated each treatment in a total of two replications)

Following sample preparation procedures described previously, samples were prepared $1 \mathrm{~h}$ before evaluation and coded with three-digit random numbers. Twenty-five-milliliter portions were then placed in 60-mL plastic soufflé cups which were capped immediately. Malundo et al. (1997) determined that the flavor profile of $50 \%$ mango homogenate generated through headspace analysis did not change significantly when the samples were left at room temperature in covered containers for up to $2 \mathrm{~h}$.

Panelists rated samples individually in partitioned sensory evaluation booths under red light. Samples were served one at a time in random order. Using scoresheets provided, panelists were requested to rate samples relative to intensity ratings of standards established during training (Table 2). They were served the standards, and unsalted crackers and water to clear their palates between samples.

Chemical analyses. Frozen samples were thawed under running tap water. For each of the 12 treatments, a $40 \mathrm{~mL}$ sample was centrifuged at $12,100 g_{\mathrm{n}}$ for $15 \mathrm{~min}$. TSS content $(\%)$ and $\mathrm{pH}$ of the supernatant fluid were determined using a refractometer (Palatte PR-101; Atago Co., Ltd., Japan) and titrator (model 230A; ATI Orion, Beverly, Mass.). TA, expressed as percentage citric acid, was calculated after titrating $10 \mathrm{~mL}$ supernatant fluid to a $\mathrm{pH}$ of 8.1 with standardized $0.1 \mathrm{~mol} \cdot \mathrm{L}^{-1} \mathrm{NaOH}$. A TSS/TA ratio for each treatment was also calculated. There were two replicates per sample.

STATISTICAL ANALYSIS. Data were analyzed using procedures of the Statistical Analysis System (SAS Institute Inc., 1990). Performance of individual panelists was evaluated using cluster analysis (PROC VARCLUS). PROC MEANS was used to calculate means and SDS of panel ratings. Flavor components which affected the response of the descriptive variables were identified by regression analysis. With mean scores across replicates as dependent variables (O’Mahony, 1995; Schutz, 1983), a reduced second order polynomial was fit to the descriptive data. The polynomial took the form: $\Sigma(y)=\beta_{1} x_{1}+\beta_{2} x_{2}+\beta_{3} x_{3}+\beta_{12} x_{1} x_{2}+$ $\beta_{13} x_{1} x_{3}+\beta_{23} x_{2} x_{3}+\delta_{12} x_{1} x_{2}\left(x_{1}-x_{2}\right)+\delta_{13} x_{1} x_{3}\left(x_{1}-x_{3}\right)+\delta_{23} x_{2} x_{3}\left(x_{2}-\right.$ $\left.\mathrm{x}_{3}\right)$, where $\Sigma(\mathrm{y})$ was the expected value of the response of the dependent flavor variables; $\mathrm{x}_{1}, \mathrm{x}_{2}$, and $\mathrm{x}_{3}$, respectively (i.e., expected value of the random variable $=$ the descriptive response), corresponded to the proportions of sugar, acid, and water in the blend; and $\beta_{1}, \beta_{2}, \beta_{3}, \beta_{12}, \beta_{13} \beta_{23}, \delta_{12}, \delta_{13}$, and $\delta_{23}$ were coefficients associated with the model terms (Snee, 1979). This 
model was derived after omitting the three-way interaction term $\left(\beta_{123} \mathrm{X}_{1} \mathrm{X}_{2} \mathrm{X}_{3}\right)$ from the full cubic polynomial since there were not enough data points for the full model. PROC STEPWISE (backward elimination) was used to determine whether a lesser number of terms than that in the reduced cubic polynomial was adequate to predict the response of the flavor variables. The criterion for the elimination was a significance level of $P \geq 0.15$. When an equation with lesser terms was sufficient, an $F$ statistic was calculated to ascertain adequacy of this model in replacing the reduced cubic polynomial (Cornell, 1983). Finally, correlation analysis (PROC CORR) was conducted to detect significant correlations between flavor properties of mangoes and chemical methods for measuring sugars and acids.

\section{Results and Discussion}

Panel Performance. Cluster analysis was used to detect outliers among the trained panelists (Powers, 1988). One individual was determined to be a consistent outlier. Therefore, evaluations of only 9 of 10 trained judges were used in subsequent analysis.

SDs (not presented) were used to assess panel performance. Based on the Empirical Rule, the range of intensities assigned by practically all the nine panelists to a treatment was within \pm 2 SDS from the mean (Ott, 1988). The descriptor intensities of the test samples fell within the ranges illustrated in Table 2.

EFFECT OF SUGARS AND ACIDS ON FLAVOR PROPERTIES. Regression analyses and calculated $F$ statistics indicated that a reduced cubic canonical polynomial was not necessary to explain the response of all descriptive variables evaluated (Table 3). Equations with fewer terms were, in fact, adequate. The models generated had relatively low cvs implying very little variation between replicates in mean panel ratings. Therefore, despite variations observed in panelists' responses, using mean scores to measure the intensity of flavor attributes as suggested previously (O’Mahony, 1995; Schutz, 1983) would seem like a logical approach.

Of the 11 properties evaluated, acid levels affected only six, namely, sweet, sour, peachy, pine, astringent, and biting. The effects of acid on sourness and astringency were expected. Acids are noted for their sour taste. In fact, these are even used as reference standards in defining the sour perception during descriptive analysis (Meilgaard et al., 1991). In addition, several investigators have characterized acids as having an astringent note (Hartwig and McDaniel, 1995; Rubico, 1993; Rubico and McDaniel, 1992; Straub, 1992). The effect of acids in potentiating sweetness was not expected but the description of acids as possessing a sweet taste by all 12 judges in a study involving freechoice profiling (Hartwig and McDaniel, 1995) provides a possible explanation.

Sugar enhanced the perception of all flavor attributes except for sour taste (Table 3). Between the two taste components studied, only sugar had any significant effect on the intensities of the descriptors bitter, sweet potato, banana, grassy, and orange peel. The positive contribution of sugar to bitter taste was expected. Although several investigators have observed a bitter flavor note in acids (Hartwig and McDaniel, 1995; Rubico, 1993; Rubico and McDaniel, 1992), present understanding of the relationship between molecular structure and taste receptor sites would tend to support the results of this study as sweet and bitter sensations are triggered by similar molecular features (Lindsay, 1988).
During training, panelists noted that flavor properties were detected more readily in diluted samples than in $100 \%$ mango homogenate. Although this observation should be verified with a time-intensity study, results presented in Table 3 indicate that increasing water level increased intensities of all flavor descriptors evaluated. In a previous study, Malundo et al. (1997) observed that concentration of volatile compounds released into the headspace increased when mango homogenate was diluted up to $50 \%$. In another study, Wilson et al. (1990) showed that the aroma and flavor thresholds of lactones, a flavor component isolated in mango, is lower (i.e., detected at lower concentrations) when placed in water than in mango puree as determined by a panel of

Table 2. Intensity ratings of standards for attributes used to evaluate mango flavor.

\begin{tabular}{|c|c|}
\hline Standard & Rating $^{2}$ \\
\hline \multicolumn{2}{|l|}{ Tastes } \\
\hline \multicolumn{2}{|l|}{ Sweet } \\
\hline Standard B & 20 \\
\hline $12 \%$ sugar & 55 \\
\hline Standard A & 63 \\
\hline $24 \%$ sugar & 124 \\
\hline $6 \%$ sugar & 150 \\
\hline \multicolumn{2}{|l|}{ Sour } \\
\hline Standard B & 29 \\
\hline $0.7 \%$ acid & 76 \\
\hline Standard A & 85 \\
\hline $1.4 \%$ acid & 117 \\
\hline $2.1 \%$ acid & 150 \\
\hline \multicolumn{2}{|l|}{ Bitter } \\
\hline Standard A & 22 \\
\hline $0.08 \%$ caffeine & 50 \\
\hline $0.15 \%$ caffeine & 100 \\
\hline \multicolumn{2}{|l|}{ Aromatics } \\
\hline \multicolumn{2}{|l|}{ Peach } \\
\hline Standard B & 26 \\
\hline Standard A & 53 \\
\hline \multicolumn{2}{|l|}{ Pine/turpentine } \\
\hline Standard A & 15 \\
\hline Standard B & 50 \\
\hline \multicolumn{2}{|l|}{ Sweet potato } \\
\hline Standard A & 19 \\
\hline Standard B & 31 \\
\hline \multicolumn{2}{|l|}{ Banana } \\
\hline Standard A & 24 \\
\hline Standard B & 38 \\
\hline \multicolumn{2}{|l|}{ Grassy } \\
\hline Standard A & 20 \\
\hline Standard B & 53 \\
\hline \multicolumn{2}{|l|}{ Orange peel } \\
\hline Standard A & 19 \\
\hline Standard B & 23 \\
\hline \multicolumn{2}{|l|}{ Chemical feeling factors } \\
\hline \multicolumn{2}{|l|}{ Astringent } \\
\hline Standard A & 22 \\
\hline Standard B & 37 \\
\hline \multicolumn{2}{|l|}{ Biting } \\
\hline Standard A & 35 \\
\hline Standard B & 46 \\
\hline
\end{tabular}


Table 3. Results of regression analyses conducted to model the responses of flavor properties to varying proportions of sugar $\left(\mathrm{x}_{1}\right)$, acid $\left(\mathrm{x}_{2}\right)$, and water $\left(\mathrm{x}_{3}\right)$ in mango homogenate.

\begin{tabular}{|c|c|c|c|c|c|c|c|c|c|c|c|}
\hline \multirow[b]{2}{*}{ Variable } & \multicolumn{11}{|c|}{ Descriptor $^{2}$} \\
\hline & Sweet & Sour & Bitter & Peachy & Pine & Sweetpotato & Banana & Grassy & Orangepeel & Astringent & Biting \\
\hline$\overline{\mathrm{x}_{1}}$ & $*$ & NS & $*$ & $*$ & $*$ & $*$ & $*$ & $*$ & $*$ & $*$ & $*$ \\
\hline $\mathrm{x}_{2}$ & $*$ & $*$ & NS & $*$ & $*$ & NS & NS & NS & NS & $*$ & $*$ \\
\hline $\mathrm{x}_{3}$ & $*$ & $*$ & & $*$ & $*$ & $*$ & $*$ & $*$ & $*$ & $*$ & $*$ \\
\hline$x_{1} x_{2}$ & $*$ & NS & NS & $*$ & NS & NS & NS & NS & NS & $*$ & $*$ \\
\hline $\mathrm{x}_{1} \mathrm{x}_{3}$ & $*$ & NS & NS & $*$ & NS & NS & NS & $*$ & NS & NS & NS \\
\hline$x_{2} x_{3}$ & $*$ & $*$ & NS & NS & $*$ & NS & NS & NS & NS & $*$ & $*$ \\
\hline $\mathrm{x}_{1} \mathrm{x}_{2}\left(\mathrm{x}_{1}-\mathrm{x}_{2}\right)$ & $*$ & NS & NS & NS & $*$ & NS & NS & NS & NS & NS & $*$ \\
\hline $\mathrm{x}_{1} \mathrm{x}_{3}\left(\mathrm{x}_{1}-\mathrm{x}_{3}\right)$ & NS & NS & $*$ & NS & NS & $*$ & $*$ & NS & NS & NS & NS \\
\hline$x_{2} x_{3}\left(x_{2}-x_{3}\right)$ & * & NS & NS & $*$ & $*$ & NS & NS & NS & NS & NS & NS \\
\hline$F$ statistic $^{\mathrm{y}}$ & $<0.01$ & 2.71 & 0.90 & 0.33 & 0.95 & 0.61 & 0.91 & 0.85 & 0.82 & 0.25 & 0.31 \\
\hline $\mathrm{CV}$ & 8.76 & 11.66 & 6.38 & 4.36 & 12.46 & 3.30 & 3.20 & 10.28 & 5.72 & 3.94 & 2.50 \\
\hline$R^{2}$ & 0.97 & 0.94 & 0.83 & 0.88 & 0.53 & 0.90 & 0.90 & 0.67 & 0.45 & 0.96 & 0.99 \\
\hline
\end{tabular}

${ }^{\mathrm{z}}$ Calculated to determine whether chosen model can replace reduced cubic canonical polynomial, $P=0.05$.

*Significant at $P=0.15$; interaction terms significant at $P=0.15$ were included only if corresponding linear terms were significant.

12 experienced judges. The effect of water was most probably due to its ability to release entrapped volatiles or disrupt apparent interactions between the mango pulp and flavor compounds, thus increasing the release of the latter (Harrison and Hills, 1997; Malundo et al., 1997). This may also indicate that the level of juiciness in mango fruit is important to flavor perception. In addition, some of the interaction terms were also significant for some of the descriptors (for sweet in particular) which is not surprising since, for example, acid affects perception of sweetness and vice versa. In addition, the levels of sugars and acids interacted to affect the responses to some of the aromatic descriptors.

The $R^{2}$ values presented in Table 3 indicated that varying levels of sugar, acid, and/or water explained much of the variations observed in mango samples in terms of the flavor descriptors sweet, sour, bitter, peachy, sweet potato, banana, astringent, and biting. Based on the discussions presented above, sugars and acids would be expected to account for much of the sweetness variations observed among the samples evaluated. In addition, acid would logically be responsible for most of the sour taste in mango. A variety of compounds contributing to the bitterness and astringency of fruit are known (Kays, 1991), however, results in Table 3 indicate that variations in sugars and acids accounted for much of the bitterness and astringent sensations in mango. In addition, the contribution of these two in explaining variations in fruity flavor notes (i.e., peachy, sweet potato, and banana) were also major. It is uncertain whether these observations were due to the psychological association of sugars and acids with fruit in the minds of the panelists or from actual chemical or physical interactions of the two taste components with other flavor compounds. However, the importance of sugars and acids as potentiators of some aromatic flavor sensations was clearly established. Sugar and acid also explained some of the variations observed among the samples in terms of the flavor notes pine/turpentine, grassy, and orange peel. However, because of the relatively low coefficients of variation $\left(R^{2}\right)$ resulting from regression analysis, it is obvious that other flavor compounds, such as aroma volatiles, also are factors in the sensation of these attributes as was shown by Malundo et al. (1996).

Correlations between flavor and CHEMical MEasureMENTS. Despite test protocols that minimize bias, use of descriptive panels to evaluate product quality is complex, time-consum- ing, subject to error due to the variability of human judgement, and, therefore, expensive. Most breeders and molecular biologists do not have access to trained panels, yet flavor quality is an important characteristic to be considered when evaluating cultivar selections. Understandably, there have been constant attempts to replace sensory panels with instrumental and/or chemical measures that are not susceptible to fatigue nor psychological fluctuations which characterize human performance (Szczesniak, 1987; Trant et al., 1981), yet relate to the sensory experience.

Chemical measures for sugar and acid levels are currently standard indices for evaluating flavor quality in fruit and vegetables. However, while sugar and acid concentrations indicate degree of ripeness, these do not necessarily relate to flavor properties (Alavoine et al., 1990). The extent to which these measurements correlate with descriptive ratings must be established (Trant et al., 1981) for them to be useful tools for breeders and others interested in screening genetic material for flavor quality.

A chemical measure can be used with confidence as a predictor of descriptive score if the simple correlation coefficient between the two variables is $\geq 0.90$. When the coefficient is $\geq 0.80$ but

Table 4. Pearson correlation coefficients $(r)$ between flavor variables and chemical measurements $(n=24)$.

\begin{tabular}{lcccc}
\hline \hline & \multicolumn{4}{c}{ Chemical measurement } \\
\cline { 2 - 5 } Flavor variable & $\mathrm{TSS}$ & $\mathrm{pH}$ & $\mathrm{TA}$ & $\mathrm{TSS} / \mathrm{TA}$ \\
\hline Taste & & & & \\
$\quad$ Sweet & $0.72^{*}$ & $0.48^{* *}$ & $-0.44^{* *}$ & $0.60^{*}$ \\
Sour & $\mathrm{NS}$ & $-0.96^{*}$ & $0.95^{*}$ & $-0.84^{*}$ \\
Bitter & $-0.49^{* *}$ & $-0.54^{*}$ & $0.48^{* *}$ & $-0.57^{*}$ \\
Aromatics & & & & \\
Peachy & $0.79^{*}$ & $\mathrm{NS}$ & $\mathrm{NS}$ & $\mathrm{NS}$ \\
Pine/turpentine & $-0.52^{*}$ & $\mathrm{NS}$ & $\mathrm{NS}$ & $\mathrm{NS}$ \\
Sweet potato & $0.41^{* *}$ & $0.74^{*}$ & $-0.72^{*}$ & $0.74^{*}$ \\
Banana & $0.47^{* *}$ & $0.63^{*}$ & $-0.64^{*}$ & $0.62^{*}$ \\
Grassy & $-0.66^{*}$ & $\mathrm{NS}$ & $\mathrm{NS}$ & $\mathrm{NS}$ \\
Orange peel & $\mathrm{NS}$ & $-0.56^{*}$ & $0.51^{* *}$ & $-0.60^{*}$ \\
Chemical feeling & & & & \\
Astringent & $\mathrm{NS}$ & $-0.96^{*}$ & $0.91^{*}$ & $-0.87^{*}$ \\
Biting & $\mathrm{NS}$ & $-0.96^{*}$ & $0.91^{*}$ & $-0.91^{*}$ \\
\hline
\end{tabular}

$\overline{\mathrm{NS},{ }^{*}, * *}$ Nonsignificant or significant at $P<0.05$ or 0.01 , respectively. 
$<0.90$ then the chemical measure may still be used as a predictor but with less confidence. A correlation $\geq 0.70$ but $<0.80$ indicate that the chemical index is only a marginal predictor of sensory ratings (Bourne, 1982).

Although there were a number of significant correlations between the descriptive and chemical properties of the experimental blends, not all of them were high enough to be considered important (Table 4). In addition, correlations that were not indicative of a cause-and-effect relationship had limited value.

The TSS/TA ratio, often used as a measure of sweetness, was not useful in measuring this descriptor in mango $(r=0.60)$, but was a reasonable predictor of the descriptors sour and astringent ( $r=-0.84$ and 0.87 , respectively), although $\mathrm{pH}$ and TA were much better predictors of the two descriptors $(r>|0.90|)$. Similar results were found for tomato (Lycopersicon esculentum Mill.) fruit (Baldwin et al., 1998). TA, pH, and TSS/TA were also very good predictors of biting $(r>|0.90|)$. TSS was not a particularly useful predictor of any of the descriptive variables evaluated., except possibly peachy aroma $(r=0.79)$. One could argue that peachy aroma and sweetness may interact in terms of the psychology of our perception. No measure was a reasonable predictor of sweetness (TSS was marginal at best with $r=0.72$ ).

\section{Conclusions}

Before this study, no in-depth research on the role of sugars and acids on the perception of mango flavor had been conducted. Therefore, in the past, the significant contribution to mango flavor attributed to these two taste components (Medlicott and Thompson, 1985) was merely an assumption perhaps based on generalizations established for other fruit.

Understanding the chemical components that contribute to flavor and how to best measure them is necessary for flavor improvement efforts in breeding programs. Data generated in this study were consistent with the present understanding of the chemical basis of flavor and results of related studies. Therefore, many of the conclusions drawn fell within the range of normal expectations. However, the extent of the influence of sugars and acids on the intensity of specific flavor notes, especially the aromatics and chemical feeling factors, was new and noteworthy. This study does not minimize the importance of volatiles and other flavor compounds on perception of mango flavor, but does establish sugars and acids as primary taste compounds in mango and as important potentiators of the aromatic components of mango flavor. However, measurements of TSS or TSS/TA were not useful predictors of sweetness, although they are often used for this purpose. Meanwhile $\mathrm{pH}, \mathrm{TA}$, and TSS/TA related well to sourness, astringency, and biting. This should be taken into account when these measurements are used to screen breeding material.

\section{Literature Cited}

Abdullah, A., T.M.M. Malundo, A.V.A. Resurreccion, and L.R. Beuchat. 1993a. Descriptive sensory profiling for optimizing the formulation of a peanut milk-based coffee whitener. J. Food Sci. 58:120-123.

Abdullah, A., A.V.A. Resurreccion, and L.R. Beuchat. 1993b. Formulation and evaluation of a peanut milk based whipped topping using response surface methodology. Lebensm.-Wiss. u.-Technol. 26:162166.

Alavoine, F., M. Crochon, and C. Bouillon. 1990. Practical methods to estimate taste quality of fruit: How to tell it to the consumer. Acta Hort. 259:61-68.
Baldwin, E.A., J.W. Scott, M.A. Einstein, T.M.M. Malundo, B.T. Carr, R.L. Shewfelt, and K.S. Tandon. 1998. Relationship between sensory and instrumental analysis for tomato flavor. J. Amer. Soc. Hort. Sci. 123:906-915.

Bourne, M.C. 1982. Food texture and viscosity: Concept and measurement. Academic Press, New York.

Cornell, J.A. 1983. How to run mixture experiments for product quality. Amer. Soc. for Quality Control, Milwaukee, Wis.

Fuchs, Y., E. Pesis, and G. Zuberman. 1980. Changes in amylase activity, starch, and sugar contents in mango fruit pulp. Scientia Hort. 13:155-160.

Galvez, F.C.F. and A.V.A. Resurreccion. 1990. Comparison of three descriptive analysis scaling methods for the sensory evaluation of noodles. J. Sensory Studies 5:251-263.

Galvez, F.C.F., A.V.A. Resurreccion, and G.O. Ware. 1995. Formulation and process optimization of mungbean noodles. J. Food Processing and Preservation 19:191-205.

Gholap, A.S., C. Bandyopadhyay, and G.B. Nadkarni. 1986. Aroma development in mango fruit. J. Food Biochem. 10:217-229.

Gowda, I.N.D., and K.H. Ramanjaneya. 1994. Studies on physicochemical characteristics of some commercial cultivars of mango. Indian Food Packer 48:45-49.

Hartwig, P. and M.R. McDaniel. 1995. Flavor characteristics of lactic, malic, citric, and acetic acids at various $\mathrm{pH}$ levels. J. Food Sci. 60:384388.

Harrison, M. And B.P Hills. 1997. Mathematical model of flavor release from liquids containing aroma-binding macromolecules. J. Agr. Food Chem. 45:1883-1890.

Holt, S.D., K.H. McWatters, and A.V.A. Resurreccion. 1992a. Validation of predicted baking performance of muffins containing mixtures of wheat, cowpea, peanut, sorghum, and cassava flour. J. Food Sci. 57:470-474.

Holt, S.D., A.V.A. Resurreccion, and K.H. McWatters. 1992b. Formulation, evaluation, and optimization of tortillas containing wheat, cowpea, and peanut flours using mixture response methodology. J. Food Sci. 57:121-127.

Kapse, B.M., D.A. Rane, and D.M. Khedkar. 1988. Correlation between bio-chemical parameters and organoleptic evaluation in mango varieties. Acta Hort. 231:756-762.

Kays, S.J. 1991. Postharvest physiology of perishable plant products. Van Nostrand Reinhold, New York.

Kumar, R., R.A. Kaushik, and A.S. Chharia. 1992. Effect of post-harvest treatments on the quality of mango during storage. Haryana J. Hort. Sci. 21:46-55.

Kundu, S. and S.N. Ghosh. 1992. Studies on physico-chemical characteristics of mango cultivars grown in the laterite tract of West Bengal. Haryana J. Hort. Sci. 21:129-134.

Lindsay, R.C. 1988. Flavors, p. 723-765. In: O.R. Fennema (ed.). Food chemistry. Marcel Dekker, Inc., New York.

Lizada, C. 1993. Mango, p. 255-271. In: B. Seymour, J.E. Taylor, and G.A. Tucker (eds.). Biochemistry of fruit ripening. Chapman and Hall, New York.

Malundo, T.M.M., E.A. Baldwin, M.G. Moshonas, R.A. Baker, and R.L. Shewfelt. 1997. Method for the rapid headspace analysis of mango (Mangifera indica L.) homogenate volatile constituents and factors affecting quantitative results. J. Agr. Food Chem. 45:2187-2194.

Malundo, T.M.M., E.A. Baldwin, G.O. Ware, and R.L. Shewfelt. 1996. Volatile composition and interaction influence flavor properties of mango. Proc. Proc Fla. State Hort. Soc. 109:264-268.

Malundo, T.M.M. and A.V.A Resurreccion. 1993. Optimization of liquid whitener from peanut extract. Lebensm.-Wiss. u.-Technol. 26:552-557.

Malundo, T.M.M., A.V.A. Resurreccion, G.O. Ware, and L.R. Beuchat. 1994. Sensory, physical, and microbiological properties of liquid whitener from peanuts. J. Food Sci. 59:338-343, 349.

Medlicott, A.P., S.B. Reynolds, S.W. New, and A.K. Thompson. 1988. Harvest maturity effects on mango fruit ripening. Tropical. Agr. 65:153-157. 
Medlicott, A.P. and A.K. Thompson. 1985. Analysis of sugars and organic acids in ripening mango fruit (Mangifera indica $\mathrm{L}$. var. Keitt) by high performance liquid chromatography. J. Sci. Food Agr. 36:561566.

Meilgaard, M., G.V. Civille, and B.T. Carr. 1991. Sensory Evaluation Techniques. CRC Press, Inc., Boca Raton, Fla.

Mitra, S. and E.A. Baldwin. 1997. Mango, p. 85-122. In: S. Mitra (ed.). Postharvest physiology and storage of tropical and subtropical fruits. CAB International, New York.

Morga, N.S., A.O. Lustre, M.M. Tunac, A.H. Balagot, and M.R. Soriano. 1979. Physico-chemical changes in Philippine Carabao mangoes during ripening. Food Chem. 4:225-234.

Narain, N., P.S. Bora, R. Narain, and P.E. Shaw. 1998. Mango, p. 1-77. In: P.E. Shaw, H.T. Chan, Jr., and S. Nagy (eds.). Agscience, Inc., Auburndale, Fla.

O’Mahony, M. 1995. Sensory measurement in food science: Fitting methods to goals. Food Technol. 49(4):72-82.

Ott, L. 1988. An introduction to statistical methods and data analysis. 3rd ed. PWS-Kent Publishing Co., Boston.

Powers, J.J. 1988. Using general statistical programs to evaluate sensory data. Food Technol. 38(6):74-82.

Rainey, B.A. 1986. Importance of reference standards in training panelists. J. Sensory Studies 1:149-154.

Rubico, S.M. 1993. Perceptual characteristics of selected acidulants by different sensory and multivariate methods. PhD diss., Oregon State Univ., Corvallis.

Rubico, S.M. and M.R. McDaniel. 1992. Sensory evaluation of acids by free-choice profiling. Chemical Senses. 17:273-289.

Rutledge, K.P. and J.M. Hudson. 1990. Sensory evaluation: Methods for establishing and training a descriptive flavor panel. Food Technol. 44(12):78-84

SAS Inst., Inc. 1990. SAS user's guide: Statistics. 6th ed. SAS Inst., Inc., Cary, N.C.

Schutz, H.G. 1983. Multiple regression approach to optimization. Food
Technol. 37(11):46-48, 62.

Selvaraj, Y., R. Kumar., and D.K. Pal. 1989. Changes in sugar, organic acids, amino acids, lipid constituents and aroma characteristics of ripening mango (Mangifera indica L.) fruit. J. Food. Sci. Technol. 26:308-313.

Shashirekha, M.S. and M.V.Patwardhan. 1976. Changes in amino acids, sugars, and nonvolatile organic acids in a ripening mango fruit (Mangifera indica, Badami variety). Lebensm.-Wiss. u.-Technol. 9:369-370.

Snee, R.D. 1979. Experimenting with mixtures. Chemtech. 9:702-710.

St. Angelo, A.J., B.T. Vinyard, and K.L. Bett. 1994. Sensory and statistical analysis in meat flavor research p. 267-290. In: F. Shahidi (ed.). Flavor of meat and meat products. Elsevier Science Publishers, Amsterdam, The Netherlands.

Straub, A.M. 1992. Power function determination of sourness and astringency and time-intensity measurements of sourness and astringency for selected acids. MS thesis. Oregon State Univ., Corvallis.

Szczesniak, A.S. 1987. Correlating sensory with instrumental texture measurements-An overview of recent developments. J. Texture Studies $18: 1-15$

Tandon, D.K. and S.K. Kalra. 1983. Changes in sugars, starch and amylase activity during development of mango fruit cv. Dashehari. J. Hort. Sci. 58:449-453.

Trant, A.S., R.M. Pangborn, and A.C. Little. 1981. Potential fallacy of correlating hedonic responses with physical and chemical measurements. J. Food Sci. 46:583-588.

Vance Publishing Corporation. 1994. Fresh trends: A profile of the fresh produce consumer. The Packer C(54):6-103.

Vazquez-Salinas, C. and S. Lakshminarayana. 1985. Compositional changes in mango fruit during ripening at different storage temperatures. J. Food Sci. 50:1646-1648.

Wilson, III, C.W. P.E. Shaw, and R.J. Knight, Jr. 1990. Importance of some lactones and 2,5-dimethyl-4-hydroxy-3(2H)-furanone to mango (Mangifera indica L.) aroma. J. Agr. Food Chem. 38:1556-1559. 